\title{
Short communication \\ Measurement of faecal sludge in-situ shear strength and density
}

\author{
JT Radford ${ }^{1 *}$ and S Sugden ${ }^{2}$ \\ ${ }^{1}$ Mott MacDonald, Demeter House, Station Road, Cambridge, CB1 2RS, United Kingdom \\ ${ }^{2}$ Water for People, 100 East Tennessee Avenue, Denver, CO 80209, USA
}

\begin{abstract}
The provision of affordable urban sanitation presents a unique set of challenges as the lack of space and resources to construct new latrines makes it necessary to empty existing pits, typically done manually with significant health risks. Various mechanised technologies have been developed to facilitate pit emptying, which are currently either tested on faecal sludge or an 'ad-hoc' simulant that (in the opinion of the tester) approximately replicates the behaviour of faecal sludge. This ranges from a watery consistency in some pour-flush latrines to the strong soil found in many alternating pits, making it difficult to evaluate the effect of changes to a design, or to compare the performance of different pit-emptying technologies produced by different organisations in different countries. This study developed the portable penetrometer, a man-portable device to physically characterise pit latrine sludge through in-situ measurement of its shear strength. The machine produces continuous profiles of shear strength with depth and is capable of testing to approximately $2.5 \mathrm{~m}$ below the slab. The portable penetrometer was manufactured and tested in the UK, before profiling approximately 30 pits in Kampala, Uganda. The resulting data are compared to the literature on the physical properties of faecal sludge, and are found to significantly extend the measured strength range with a maximum value approximately 5 times higher than previously reported. The effect of physical remoulding is identified through comparison of data from undisturbed and remoulded strength tests and highlights the potential to increase the 'pumpability' of faecal sludge through in-pit fluidisation.

The implications for the development of pit-emptying technologies and synthetic sludge simulants are discussed, and potential further work is identified. These include studies on factors affecting pit function and fill-up rates as well as scientific tests on the effect of modifications to latrines. In both cases any change in the physical properties of the faecal sludge can be identified through repeated profiling using the portable penetrometer. It is hoped that the penetrometer can contribute to an improved understanding of the physical properties of faecal sludge and the factors affecting pit function, supporting the development of improved faecal sludge management services.
\end{abstract}

Keywords: Density, faecal sludge, pit latrine, sanitation, shear strength

\section{ABBREVIATIONS}

$\begin{array}{lll}\text { AIT } & - & \text { Asian Institute of Technology } \\ \text { ASTM } & - & \text { American Society for Testing and Materials } \\ \text { BCG } & - & \text { Boston Consulting Group } \\ \text { JMP } & - & \text { Joint Monitoring Programme } \\ \text { UNDESA } & - & \text { United Nations Department of Economic } \\ & & \text { and Social Affairs } \\ \text { UN-HABITAT } & - & \text { United Nations Human Settlements } \\ & & \text { Programme } \\ \text { UNICEF } & - & \text { United Nations Children's Fund } \\ \text { VIP } & - & \text { Ventilated improved pit latrine } \\ \text { WHO } & - & \text { World Health Organisation }\end{array}$

\section{NOMENCLATURE}

$A-$ Projected area of ball $\left(\mathrm{m}^{2}\right)$

$D$ - Diameter of ball (m)

$F \quad-$ Shaft force during penetration $(\mathrm{N})$

$K$ - Herschel-Bulkley fluid model factor

$n$ - Fluid power law index

$N_{b}$ - Full-flow penetrometer correction factor

$q$ - Specific resistance to penetration $\left(\mathrm{N} \cdot \mathrm{m}^{-2}\right.$ or $\left.\mathrm{Pa}\right)$

To whom all correspondence should be addressed.

푱 +44 (0)1223 463553; e-mail: james.radford@mottmac.com

Received 22 February 2013; accepted in revised form 10 January 2014. $v-$ Penetration velocity $\left(\mathrm{m} \cdot \mathrm{s}^{-1}\right)$

$\gamma$ - Shear strain rate $\left(\mathrm{s}^{-1}\right)$

$\delta$ - Penetration distance $(\mathrm{m})$

$\tau$ - Shear strength $\left(\mathrm{N} \cdot \mathrm{m}^{-2}\right.$ or $\left.\mathrm{Pa}\right)$

$\tau_{0} \quad$ - Yield strength $\left(\mathrm{N} \cdot \mathrm{m}^{-2}\right.$ or Pa)

\section{INTRODUCTION}

Providing adequate sanitation to a rapidly growing urban population is one of the greatest challenges facing our generation. An estimated 2.5 billion people lack access to improved sanitation (WHO/UNICEF, 2012), which contributes to approximately 840000 child deaths per year from diarrhoeal disease (UNICEF, 2012). Urban informal settlements provide a very different set of challenges to those encountered in rural areas as many houses do not have space for individual toilets and those that do are typically unable to dig a new pit when their latrine is full. An estimated 1.2 billion urban dwellers have limited access to faecal sludge management services (BCG, 2012). This problem is set to get worse with urban populations in developing countries forecast to almost double to over 5 billion by 2050 (UNDESA, 2012). Much of this growth will be in informal settlements or slums which already house over 860 million people (UN-HABITAT, 2012).

Regular pit emptying is a necessary service if latrines are to provide a sustainable service in high density urban settlements. The vyura (frogmen) of Dar es Salaam earn a living from manually emptying pits - spending up to 6 hours at a time waist deep 
in faecal sludge without protective clothing. In addition to the wide range of diseases they may contract, pit emptiers are also at risk from the collapse of unlined pits and are often stigmatised by the communities they serve, forcing them to work after dark and to dump the extracted sludge illicitly in the nearest available sewer or stream (Eales, 2005).

Significant work has been done to develop affordable mechanised pit emptying technologies as alternatives to large vacuum tankers for high-density urban settlements. However, there is very limited information available on the physical properties of pit latrine sludge on which to base design decisions. Furthermore, latrine sludge is observed to vary widely from the 'watery' contents of some pour-flush vaults to the strong soil found in alternating VIPs. The absence of a method to physically characterise latrine sludge has prevented the objective and quantitative comparison of the performance of different technologies and comparisons are instead made on the basis of anecdotal evidence and personal preference.

This paper presents a methodology for the physical characterisation of pit latrine sludge according to its density and shear strength. A device has been developed for testing latrine sludge which produces a continuous shear strength profile with depth, and the results of an initial study testing 30 pits in Kampala, Uganda, are presented.

\section{METHODS}

\section{Shear strength}

In this study faecal sludge is treated analogously to weak marine sediments and its resistance to flow is characterised according to its undrained shear strength. This is considered a more intuitive measure than viscosity, which was reported in the only known study in the literature (Bösch and Schertenleib, 1985), because consolidated pit latrine sludge does not readily flow, behaving more like a soil than a fluid. The HerschelBulkley fluid model is applied, such that shear strength $(\tau)$ is a function of yield stress $\left(\tau_{0}\right)$ and shear strain rate $(\gamma)$ according to the power law:

$$
\tau=\tau_{0}+K \cdot \gamma^{n}
$$

The portable penetrometer consists of a plastic ball and extensible shaft suspended from a load cell, which records the resistance to penetration. The major advantage of this design over strain-gauging the shaft (Stewart and Randolph, 1994) or using in-ball measurement (Kuo, 2011) is that none of the delicate and expensive electronics pass into the latrine. This also simplifies the design of the extensible shaft as no data or power cables need to pass down the shaft to the measurement device. A small direct current motor coupled to a leadscrew drives the ball through the sludge and velocity is recorded using a draw wire potentiometer connected to a data logger. The whole system is man-portable, powered by a $12 \mathrm{~V}$ lead acid battery and connected to a laptop via USB cable for data logging purposes. Development of the device is on-going and further technical details are available from the design report (Radford, 2012).

The device is a form of full-flow penetrometer, which produces a continuous profile of undrained shear strength without the need for empirical correlations or pore pressure adjustments (Stewart and Randolph, 1994). Its operating principle is demonstrated in Fig. 1. The specific resistance to penetration $(q)$ is calculated by dividing the shaft force during penetration $(F)$ by the projected area of the ball $(A)$. The shear strength $(\tau)$ of

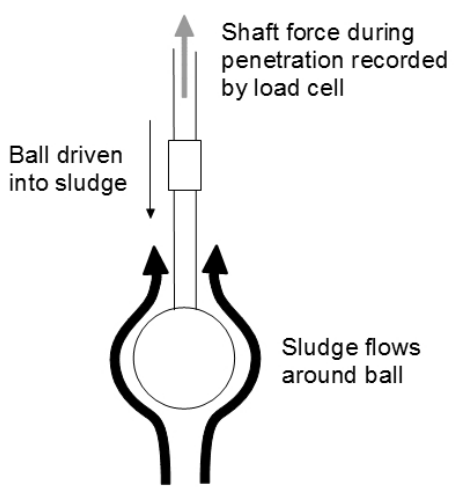

Figure 1

Schematic demonstrating the operating principle of the portable penetrometer

the sludge is then obtained by dividing the specific resistance to penetration by a correction factor, $N_{b}$ :

$$
\tau=\frac{q}{N_{b}}=\frac{F}{A \cdot N_{b}}
$$

A correction factor $\left(N_{b}\right)$ of 10.5 has been selected, as it is used extensively in geotechnical studies (e.g. Chung, 2005). Further work is planned to calibrate the portable penetrometer against a laboratory rheometer to validate this selection of $N_{b}$. The shear strain rate at the surface of the ball can be estimated as twice the penetration velocity $(v)$ divided by the ball diameter (D) (Randolph and Andersen, 2006):

$$
\gamma=\frac{2 \cdot v}{D}
$$

The ball diameter was set at $40 \mathrm{~mm}$ to enable 2 tests to be conducted through a $100 \mathrm{~mm}$ squat hole without overlap of their zones of influence, which extend 1.25 ball diameters (i.e. $50 \mathrm{~mm}$ ) on either side of the shaft. The minimum acceptable ratio of ball to shaft area for which the full-flow mechanism holds is 5:1 (Yafrate et al., 2007), which therefore set a maximum shaft diameter of $18 \mathrm{~mm}$. The system was designed to measure strengths up to a maximum of $2000 \mathrm{~Pa}$ on the basis that the strongest recorded sludge in the literature, reported by Bösch and Schertenleib (1985), had a shear strength of approximately $400 \mathrm{~Pa}$ (Radford and Fenner, 2013).

The first penetration stroke through undisturbed sludge records a shear strength profile that is continuous with depth for the consolidated sludge in the pit, at a shear strain rate of $1 \mathrm{~s}^{-1}$ and ambient temperature. As the ball is driven down through the sludge the shaft is extended in sections until it reaches the bottom of the pit or the maximum shaft length of $2.5 \mathrm{~m}$. The ball is then cycled up and down 10 times to fully remould the sludge, breaking down any physical structure in the material (Chung, 2005). The remoulded sludge is then thoroughly characterised by testing at 5 different shear strain rates, with 3 repeats at each speed, to determine the material's shear strength-strain rate relationship. Penetration tests were carried out at shear strain rates ranging from 0.3 to $13.2 \mathrm{~s}^{-1}$, which cover both the standard geotechnical reference rate of $1 \mathrm{~s}^{-1}$ (Chung, 2005) and the $9.4 \mathrm{~s}^{-1}$ rate used by Bösch and Schertenleib (Radford and Fenner, 2013). Although designed to conduct 2 tests through a latrine squat hole, it did not prove practical to set up and level the penetrometer with sufficient accuracy for both tests to be completed, so only a single test was conducted on undisturbed sludge in each pit. 

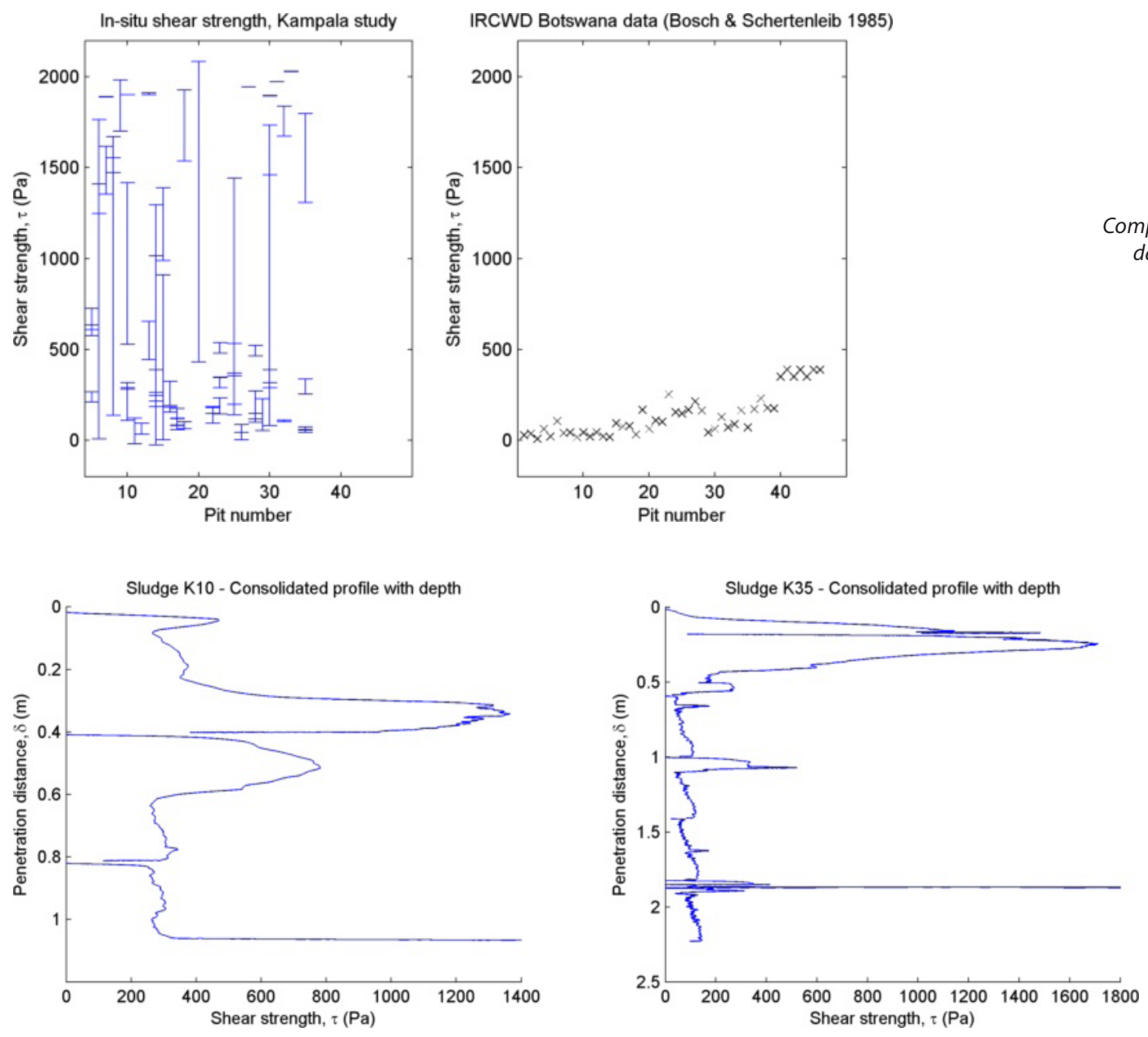

Figure 2

Comparison of shear strength data with the literature

\section{Density}

A $60 \mathrm{~m} \ell$ syringe was modified for taking samples of sludge by drilling an $8 \mathrm{~mm}$ diameter hole in its end. It was then attached to two $2.5 \mathrm{~m}$ lengths of plastic pipe that fitted snugly over the syringe and plunger so that samples could be taken at depth from within the pit. After shear strength profiling was complete the portable penetrometer was removed and a density sample was extracted from as deep as possible in each pit. The volume was measured using the graduations on the syringe before the sample was transferred into a container and weighed using the portable penetrometer's load cell.

Following review of the density data it was found that a number of the samples were apparently significantly less dense than water, which was attributed to systematic errors in the methodology for measuring sample volume. The majority of pits were therefore re-sampled during subsequent fieldwork using the same apparatus, and the samples were stored in labelled airtight containers. The bulk density of each sample was determined the following day in a laboratory environment according to standard procedures (ASTM, 2009).

\section{RESULTS AND DISCUSSION}

\section{Shear strength}

A total of 30 latrines were tested in Kampala, Uganda, in the community of Nsambya Gogonya. The study area spans a valley and as a result the latrines varied in construction from very deep unlined pits sited well above the water table, to shallow lined vaults down in the valley.

Figure 2 compares the shear strength data from the profile through undisturbed sludge in each pit with the data reported by Bösch and Schertenleib (1985) whose viscosities have been converted into shear strengths by Radford and Fenner (2013). The large ranges in shear strength reported in the present study reflect changes in strength over the depth of the pit, whereas Bösch and Schertenleib recorded the highest strength sludge that could be removed using different vacuum tankers, yielding a single reading for each latrine which does not represent the maximum strength of sludge in the latrine. It is evident that the present investigation has increased the maximum reported strength of pit latrine sludge by a factor of approximately 5, from $400 \mathrm{~Pa}$ to over $2000 \mathrm{~Pa}$. The actual strength of the sludge found in 7 of these pits exceeds $2000 \mathrm{~Pa}$, as indicated by the very small strength ranges recorded at the upper end of the scale where the portable penetrometer reached its maximum reading. It is noted that almost every pit (87\%) in this study contained some weak sludge of comparable strength to that previously reported, however the majority of pits (60\%) also contained sludge stronger than the previously reported maximum.

This variability in pit contents is further demonstrated by Fig. 3, which shows 2 shear strength profiles that are continuous with depth through different pits. The breaks in the data and associated horizontal lines occurring every $0.4 \mathrm{~m}$ correspond to the extension of the shaft in sections as the ball is driven through the full depth of the pit. 


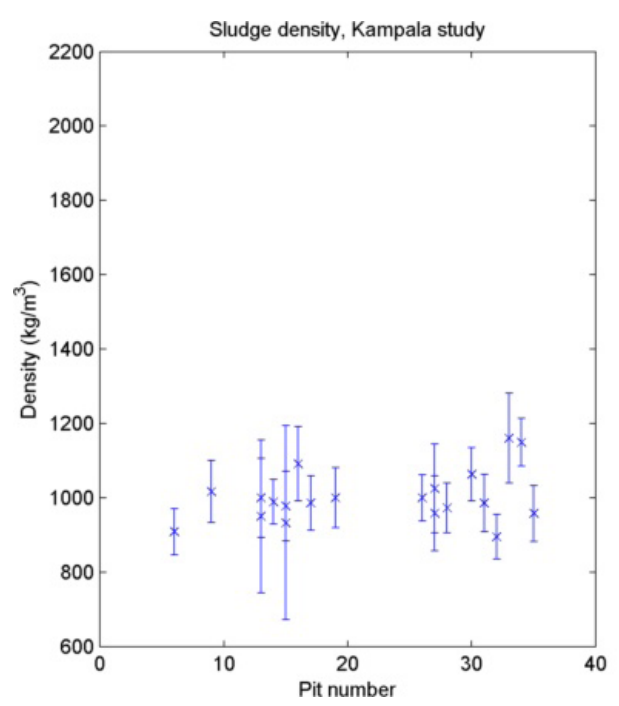

It is evident that both pits are highly variable with depth and that the sludge observed at the top of the pit is not necessarily representative of the pit contents. The presence of a high-strength crustal layer at the surface overlaying weak sludge below, as shown on the right in Fig. 3, was repeatedly observed, with crustal layers 5-15 times stronger than the underlying sludge. On observing the surface of the pit one may conclude that the sludge is too strong to be removed with mechanised pit-emptying technologies, whereas actually the majority of the pit volume is filled with a weak, watery sludge. The pit would also appear to be functioning well with natural degradation processes producing a thick, strong sludge, whereas in reality the opposite is true.

The effect of remoulding the sludge to break down its physical structure was also investigated and the ratio of the undisturbed and remoulded shear strengths, termed sensitivity, calculated for all pits. Sensitivities ranged from 1 to more than 10 , with 3.3 considered representative of the latrines sampled during this study. This indicates that there is significant scope to improve pit-emptying performance by first fluidising the pit contents, thereby reducing their strength to the lower, remoulded state and increasing the volume of material that can be emptied from the pit. Initial laboratory tests at reduced scale have successfully fluidised sludge with shear strengths of approximately $1000 \mathrm{~Pa}$ through the injection of air into the bottom of the pit (Radford and Fenner, 2013).

It is noted that the remoulded strength data recorded in Kampala are comparable to the strengths reported by Bösch and Schertenleib (1985), who removed samples from the pit for laboratory testing. It is possible that the process of sampling and transporting the faecal sludge caused sufficient remoulding to produce a significant decrease in strength. In-situ testing of shear strength is therefore recommended as the most accurate method of characterising the undisturbed contents of pit latrines.

\section{Density}

Density data for samples collected from 18 of the pits are presented in Fig. 4 below. The samples from Kampala have a mean density of $1001 \mathrm{~kg} \cdot \mathrm{m}^{-3}$ which is significantly lower $(p$ $=0.01$, Cohen's $d=1.77$ ) than the $1423 \mathrm{~kg} \cdot \mathrm{m}^{-3}$ reported by Bösch and Schertenleib (1985); however, it is comparable to
IRCWD Botswana data (Bosch \& Schertenleib 1985)

Comparison of density data with the literature data recently reported for septic tank 'wet bottom sludge' with a density of 1 092-1 $159 \mathrm{~kg} \cdot \mathrm{m}^{-3}$ (AIT, 2012).

It is suggested that the sludges sampled in Botswana contained significant amounts of sand and earth which increased the sludge bulk density due to their high specific gravity. During Bösch and Schertenleib's study it was observed that the addition of sand to cover latrine contents after each use was commonplace (Hawkins, 2012). In addition to this many of the pits were unlined and samples were taken after attempted emptying - in some cases the report notes that pits collapsed upon emptying and the sample consisted of 'dry sand'.

\section{Further work}

The data presented here indicates that pit latrine sludge is both significantly stronger and less dense than previously reported in the literature. However, this study only characterised the contents of 30 latrines in a single community in Kampala, and a larger study testing hundreds of pits across multiple cities is now required to develop a better understanding of the range of physical characteristics of faecal sludge. This will provide the data necessary to inform the design of improved pit-emptying technologies and produce the best information to date on the range and distribution of strengths of faecal sludge, helping to define the potential market size for different technologies according to their emptying performance.

The portable penetrometer enables studies to test the effect of different factors on pit function and fill-up rate, as the sludge volume and strength can be directly measured without the need to empty the pit or remove samples. The characterisation process can be repeated on a regular basis to identify how the sludge changes with time and to measure the difference in sludge properties between 'experimental' and 'control' pits. Possible tests could investigate the effect of a change in pit management practice (e.g. adding additional water) or a technical innovation (e.g. installing a drain-pipe and soakaway).

Work is on-going at Mott MacDonald and the University of Cambridge to develop improved synthetic sludge simulants that replicate the full range of shear strengths and densities reported for faecal sludge. These will provide a material on which to test prototype pit-emptying technologies which is 
safe to handle and more representative of the physical characteristics of faecal sludge.

\section{CONCLUSIONS}

A sample of 30 pit latrines in Kampala, Uganda have been physically characterised using the portable penetrometer, a bespoke device developed during this study. The maximum undisturbed sludge shear strengths were approximately $2000 \mathrm{~Pa}, 5$ times stronger than previously reported in the limited literature on the subject. The faecal sludge tested here was found to have a sensitivity of 3.3, indicating significant potential to increase emptying capabilities through in-pit fluidisation. Density samples from these pits were significantly lower than reported by Bösch and Schertenleib (1985) and had a mean value of $1001 \mathrm{~kg} \cdot \mathrm{m}^{-3}$, which is broadly in agreement with a recent study by AIT (2012).

The portable penetrometer developed here has demonstrated an ability to measure both the undisturbed and remoulded shear strengths of faecal sludge in-situ, and its use is therefore recommended for future studies. Continuous shear strength profiles through the pits have demonstrated an unexpected variability within individual latrines, with the strength of layers found at different depths varying by a factor of up to 15.

Finally, further studies have been suggested including the widespread physical characterisation of faecal sludge, controlled scientific studies into the factors affecting pit function and fill-up rates, and the development of improved synthetic sludges to support the testing of new pit-emptying technologies.

\section{ACKNOWLEDGEMENTS}

This investigation received funding from Water for People and the London School of Hygiene and Tropical Medicine, in a contract managed by Engineers Without Borders-UK. Part of the work was undertaken by the first author as a Visiting Researcher at the University of Cambridge. The authors would like to thank Manus Coffey, Dr Richard Fenner, Alistair Ross, the workshop staff in the Engineering Department and the Water for People team in Kampala for their assistance and advice.

\section{REFERENCES}

AIT (ENVIRONMENTAL ENGINEERING MANAGEMENT OF AIT) (2012) Final Report: Assessment of Faecal Sludge Rheological Properties. AIT, Pathumthani. $60 \mathrm{pp}$

ASTM (2009) ASTM Standard D7263-09: Standard Test Methods for Laboratory Determination of Density (Unit Weight) of Soil Specimens. ASTM International, West Conshohocken. 7 pp.

BCG (2012) Omni Ingestor global market sizing project: Final deliverable part B: Complete compendium. BCG, Seattle. 33 pp.

BÖSCH A and SCHERTENLEIB R (1985) Emptying on-site excreta disposal systems (IRCWD Report 03/85). EAWAG, Dübendorf. 77 pp.

CHUNG SF (2005) Characterisation of soft soils for deep water developments. PhD thesis, University of Western Australia, Perth. 349 pp.

EALES K (2005) Bringing Pit Emptying out of the Darkness, Sanitation Partnership Series: Manual Pit Emptying. Building Partnerships for Development in Water and Sanitation, London. 9 pp.

HAWKINS P (2012) Personal communication, 30 October 2012. Mr Peter Hawkins. Senior Water Sanitation Specialist, World Bank Water and Sanitation Program - Africa Region, The World Bank, Upper Hill Road, PO Box 30577, 00100, Nairobi, Kenya.

KUO MYH (2011) Deep ocean clay crusts: behaviour and biological origin. PhD thesis, University of Cambridge, Cambridge. 237 pp.

RADFORD JT (2012) Latrine sludge characterisation: Design Report (Ref. 302197/Design Report/A). Engineers Without Borders-UK, London. 17 pp.

RADFORD JT and FENNER RA (2013) Characterisation and fluidisation of synthetic pit latrine sludge. J. Water, Sanit. Hyg. Dev. 3 (3) 375-382.

RANDOLPH MF and ANDERSEN KH (2006) Numerical analysis of T-bar penetration in soft clay. Int. J. Geomech. 6 411-420.

STEWART DP and RANDOLPH MF (1994) T-Bar penetration testing in soft clay. J. Geotech. Eng. 120 (12) 2230-2235.

UN-HABITAT (2012) State of the World's Cities 2012/13: Prosperity of cities. United Nations, Nairobi. 152 pp.

UNDESA (2012) World Urbanisation Prospects: The 2011 Revision: Highlights. United Nations, New York. 33 pp.

UNICEF (2012) Pneumonia and Diarrhoea: Tackling the Deadliest Diseases for the World's Poorest Children. UNICEF, New York. $77 \mathrm{pp}$.

WHO/UNICEF (JMP FOR WATER SUPPLY AND SANITATION) (2012) Progress on Drinking Water and Sanitation: 2012 Update. United Nations, New York. 61 pp.

YAFRATE NJ, DE JONG JT and DE GROOT DJ (2007) The influence of full-flow penetrometer area ratio on undrained strength measurements. $6^{\text {th }}$ International Conference on Offshore Site Investigation and Geotechnics. Society for Underwater Technology, London. 
http://dx.doi.org/10.4314/wsa.v40i1.22 Available on website http://www.wrc.org.za

ISSN 0378-4738 (Print) $=$ Water SA Vol. 40 No. 1 January 2014 ISSN 1816-7950 (On-line) = Water SA Vol. 40 No. 1 January 2014 